FREQUENT ATTENDERS' EXPERIENCES OF ENCOUNTERS WITH

HEALTHCARE PERSONNEL: A SYSTEMATIC REVIEW OF QUALITATIVE

STUDIES

A short running title: Frequent attenders' encounters in healthcare

Moona HUHTAKANGAS, MSc, Department of Nursing Science and Health

Management, University of Oulu, Finland, PL 5000, 90014 University of Oulu, Oulu,

Finland, moona.huhtakangas@oulu.fi, ORCID: 0000-0002-5998-883X

Anna-Maria TUOMIKOSKI, PhD, Oulu University of Applied Sciences (Principal

Lecturer), The Finnish Centre for Evidence-Based Health care: A JBI Centre of

Excellence

Helvi KYNGÄS, professor, Department of Nursing Science and Health Management,

University of Oulu, Medical Research Centre, University Hospital of Oulu, Oulu,

Finland

Outi KANSTE, docent, Department of Nursing Science and Health Management,

University of Oulu, Oulu, Finland

\title{
Acknowledgements
}

None.

This article is protected by copyright. All rights reserved. 


\section{Word count: 5198}

\section{Abstract}

In order to study frequent attenders' lived experience rather than measuring demographics such as socioeconomics, the aim of this study was to synthesise frequent attenders' experiences of their encounters with healthcare personnel. Scopus, CINAHL, PsycARTICLES, and PubMed (Medline) databases were searched in May 2020. The identified studies were screened by title and abstract $(n=1794)$ and full-text $(n=20)$. Findings from the included studies $(n=6)$ were pooled using meta-aggregation. The findings show that difficulties in resolving frequent attenders' situations may create "service circles", making patients frustrated with their situation; frequent attenders' own expertise with their condition should be recognised and valued alongside that of healthcare professionals when performing collaborative care; a lack of empathy and disparagement may make frequent attenders feel misunderstood and unappreciated; frequent attenders should be recognised as individuals by taking their circumstances into account and providing support accordingly. Frequent attenders' experiences demonstrate the importance of shared decision-making, continuity of care, and acknowledgement of frequent attenders' individual circumstances. Identifying frequent attenders' varied service needs by synthesising their experiences is a practical way of organising patient-centred healthcare services. 
Keywords: Delivery of Health Care; Health Services Needs and Demand; Patient

Participation; Patient Satisfaction; Professional-Patient Relations; Systematic review 


\section{INTRODUCTION}

A small proportion of patients known as frequent attenders (FAs) use healthcare services more frequently than the average patient: they represent roughly $5-8 \%$ of all healthcare visitors but account for 21-28\% of healthcare visits (LaCalle \& Rabin, 2010) and around 55\% of all healthcare costs (Wammes et al., 2018). In addition, they experience social and economic difficulties and require follow-up consultations (Kivelä et al., 2018). FAs may have several chronic health conditions, poor perceived health, mental illness, and have a low quality of life (LaCalle \& Rabin, 2010). If FAs experience difficulties obtaining regular care (e.g. have accessibility or continuity problems in primary care) (Hudon et al., 2016), they tend to seek care from emergency care or multiple healthcare sectors (Lyons et al., 2017). The phenomenon of interest of this study, frequent attendance, leads to overcrowding in emergency departments and FAs often use emergency departments for inappropriate reasons. For example, they may consider their situation as serious (although objectively not considered as such) and seek immediate care (Burns et al., 2017).

FAs are a very heterogeneous patient group because their individual attributes are highly varied. In addition, frequent attendance has been defined in different ways. For example, it has been defined based on making a certain number of visits over a specific period of time (Vedsted \& Christensen, 2005) and also in terms of the frequency of attendance or costs caused relative to the wider patient population (Vedsted \& Christensen, 2005). Also, FAs may be divided into subgroups based on the type of 
health service that they use frequently (e.g. FAs of emergency care) or based on their symptoms (e.g. FAs with medically unexplained symptoms). Similarly, interventions may be targeted at specific FA subgroups (Haroun et al., 2016).

Patients' experiences of the ways they are encountered influence their views of the healthcare system. Patients typically consider encounters successful if they experience continuity of care and feel that the healthcare professional is competent and takes them seriously. Conversely, feelings of disappointment and indifference are associated with negative patient encounters (Salokekkilä, 2011). Patients have several expectations of consultations in terms of both the attitude and approach of the healthcare professional and the outcomes of the care (e.g. reduction in symptoms) (Bowling et al., 2012). Patient-centred care has attracted considerable attention in recent years because it has been found to improve the quality of healthcare and reduce patients' need for services (Delaney, 2018). The application of patient-centredness during patient encounters involves acknowledging the patient's own interpretation of their condition and the importance of the relationship between the patient and the healthcare professional (Langberg et al., 2019). Patient-centredness also entails acknowledging the patient's preferences and needs while simultaneously providing support so as to enable the patient's participation in shared decision-making (Kitson et al., 2013). Patients tend to express high satisfaction with care when they participate in shared decision-making and can consult with healthcare professionals who are familiar with their medical history (Altin et al., 2016). The arrangement of care for FAs varies widely, particularly in terms of how many and what types of healthcare professionals participate in their care, and also in terms of the FAs' involvement in their treatment plan (Vehko et al., 2018). 
Frequent attendance has mainly been studied by patient profiling. However, the ways in which FAs are encountered have attracted less attention, and the available data are somewhat contradictory. Dinkel et al. (2016) found that strong relationships between family physicians and FAs were not associated with frequent attendance. Low levels of interpersonal communication also do not appear to be strongly associated with frequent attendance (Hudon et al., 2016). Patient-physician relationships based on collaboration have been found to reduce FAs' healthcare costs (Ganguli et al., 2017), and low satisfaction with care is associated with frequent attendance (Koskela et al., 2010). In their literature review, Hudon et al. (2020) examined how case management interventions improve outcomes for FAs. They noted that the quality of the relationship between the case manager and the FA is essential regarding the successfulness of case management. Meaningful relationships improve FAs' engagement in their care and their health condition, and decreases healthcare use. A deeper understanding of the encounters between FAs and healthcare professionals is needed in order to identify FAs's service needs beyond specific attributes, such as socioeconomic status or number of health conditions. This systematic literature review of qualitative studies using metaaggregation synthesizes existing knowledge about FAs' experiences of their encounters with healthcare personnel. The research question is: how do FAs experience their encounters with healthcare personnel?

This article is protected by copyright. All rights reserved. 


\section{METHODS}

\subsection{Data sources and search strategy}

This review follows the Joanna Briggs Institute's (JBI) guidelines for systematic reviews of qualitative evidence. First, the studies identified in database search were screened by title and abstract, and then by full text. The selection of studies was based on specific inclusion and exclusion criteria. Second, the quality of the included studies was assessed. The data were extracted, and the data were analysed using metaaggregation. (Lockwood et al., 2017). The Preferred Reporting Items for Systematic Reviews and Meta-Analyses (PRISMA) checklist was followed where applicable. Before conducting the database search, various search terms and combinations of search terms were tested in order to develop the most suitable search strategy. Studies were identified by searching four databases (Scopus ,CINAHL, PubMed (Medline), and PsycARTICLES) in May $5^{\text {th }}$. The search strategy was developed with the assistance of an information specialist. The full search strategies are provided in Table 1. Duplicates were removed using Mendeley. Two researchers ( $\mathrm{MH}$ and $\mathrm{OK})$ screened the studies independently in two stages: first by title and abstract, and second by full text. After each step, the researchers discussed which studies to include until a consensus was reached. The reference lists of articles selected for inclusion were then searched manually to identify additional potentially relevant articles. The grey literature was searched in MedNar (see Table 1). The database search was conducted in May 2020. 


\subsection{Study selection}

The inclusion criteria were developed using PICo (P: participants, I: phenomenon of interest, and Co: context). The following inclusion criteria were used: 1) the study focused on adult FAs, 2) FAs' experiences of their encounters with healthcare personnel were examined, 3) the study was qualitative, 4) the article presented original research, and 5) the article's full text was available in English. The following exclusion criteria were used: 1) the study only examined FAs' reasons for seeking care, and 2) the study focused on FA sub-populations such as FAs with mental health or alcohol problems, or child and adolescent FAs. Regarding context, there were no exclusion criteria based on in which healthcare sector the study was conducted (i.e. studies conducted in both primary care and secondary care were included).

The database search identified 1794 articles after duplicates were removed. After excluding 1774 articles based on titles and abstracts, the full texts of 20 articles were reviewed. Of these, 13 were excluded because they did not meet the inclusion criteria (Figure 1), leaving seven studies for critical appraisal. No further studies were identified from MedNar, or by manual searching. One study was excluded based on critical appraisal, leaving six studies to be included in the qualitative synthesis.

\subsection{Quality assessment}


The JBI Qualitative critical appraisal criteria (includes in total ten criteria) were used for quality assessment (Lockwood et al., 2017). Only studies satisfying at least five of these ten criteria were included in the analysis. Two researchers (MH and AT) scored the studies independently and reached agreement on their ratings.

\subsection{Data extraction and synthesis}

Data extracted from the included articles were the citation of the article, country of publication, study purpose, participants, methodology (study setting, data collection, and data analysis) and key findings. Only findings relevant to this literature review's research question were extracted.

Data synthesis was performed using the meta-aggregation approach, developed by the JBI (Lockwood et al., 2017). First, findings (i.e. the study's authors' analytic interpretation of their data) were extracted from the included studies together with an illustration (a direct quotation relating to the extracted finding). The objective of the meta-aggregation approach is not to re-interpret the findings presented in the included studies but to consider the primary author's findings as they are originally presented. Therefore, a finding was defined as a verbatim extract of the interpretation originally offered by the authors of the included study. Second, levels of credibility were assessed based on the congruence between a finding and the accompanying illustration; each finding was classified as being unequivocal, equivocal, or unsupported. If a finding's level of plausibility was classified as unsupported, it was not included in the synthesis. 
Findings with illustrations are presented in Supplement 1. Unsupported findings are presented in Supplement 2. Third, the findings were categorised into categories based on similarity of content. According to meta-aggregation approach, each category had to include at least two findings. Finally, synthesised findings were constructed by aggregating the categories based on similarity of content. Each synthesised finding had to include at least two categories. The meta-aggregation approach aims at creating recommendations for practice (Lockwood et al., 2017).

In accordance with the JBI's guidelines for systematic reviews of qualitative evidence, the ConQual approach was used to establish confidence in the evidence. The ConQual summary of findings includes a calculated ConQual score for each synthesised finding (Munn et al., 2014). In ConQual, a score is calculated for each synthesised finding based upon the strength of the evidence that informs the included findings. The overall ConQual score can be high, moderate, low or very low based upon measures of dependability and credibility of the included studies. The ConQual Score was calculated as follows: first, included qualitative research studies start ranked as high. A dependability score is calculated upon five questions from the critical appraisal criteria (questions Q2-Q4, Q6, Q7). The score was downgraded one level if only two or three responses to the five questions were yes, and was downgraded two levels if none or one questions were yes. The level of credibility of each individual finding forms the second part of the score. Levels of credibility reflect the degree of congruence between a finding and the accompanying illustration; each finding was classified as being unequivocal, credible, or not supported. If findings included classifications of both 
unequivocal and credible, the score was downgraded one level. If findings were classified as equivocal, the score was downgraded two levels. (Munn, et al., 2014).

\section{RESULTS}

\subsection{Overview of the reviewed studies}

The results of the data extraction are presented in Table 2. The included studies were conducted in the United Kingdom, USA and Sweden. The year of publication ranged from 2000 to 2013. The numbers of interviewed FAs ranged from nine to 33. Most of the studies were conducted in primary care settings. One study included FAs with multiple emergency department visits. The definitions of FAs were heterogeneous: FAs were defined as a certain percentile of the patient population or based on the number of consultations they had over a certain period of time. One study did not clearly specify its definition of FAs. The studies examined encounters between FAs and healthcare personnel. Half of the studies did not clearly specify all parties that were regarded as healthcare personnel. Two of the studies examined encounters between FAs and physicians and one examined encounters between FAs and both physicians and reception staff.

\subsection{Data synthesis: The ways frequent attenders are encountered by healthcare} personnel 
In total, 37 findings (themes and metaphors) were extracted from the included studies $(\mathrm{n}=6)$, and 13 categories were created based upon similarities in meaning across the 37 findings (Table 3). In the final step of the synthesis, four synthesised findings were developed based on the 13 categories. The first synthesised finding Difficulties in resolving FAs' situations may create "service circles", making patients frustrated with their situation was based on three categories: FAs feel they are referred from one healthcare professional to another; The care received and its outcomes do not meet FAs' expectations; FAs seek reassurance through consulting, during which the healthcare professional can significantly increase FAs' future attendance. The second synthesised finding FAs' own expertise with their condition should be recognised and valued alongside the expertise of healthcare professionals when performing collaborative care was based on three categories: FAs regard specialist-client relationships as collaborations with healthcare professionals; FAs want their own interpretation of their condition and situation to be valued and taken into consideration; FAs respect the healthcare professional as an authority and expert in managing and treating their symptoms. The third synthesised finding A lack of empathy and disparagement may make FAs feel misunderstood and unappreciated was based on four categories: FAs feel they are disrespected or stigmatised by healthcare professionals; FAs feel they are not worth caring for; FAs perceive a lack of empathy and feel their needs are diminished; FAs feel the healthcare professionals do not understand them or their condition. The fourth synthesised finding FAs should be recognised as individuals by taking their circumstances into account and providing support accordingly was based on three categories: FAs appreciate having their individual situation and condition acknowledged 
and being treated accordingly; FAs value healthcare professionals also acknowledging other (non-medical) aspects of their life that they consider important; FAs emphasised the role of healthcare professionals' and the clinic as a whole in making FAs feel welcomed.

\subsubsection{Difficulties in resolving FAs' situations may create service circles, making patients frustrated with their situation}

Three categories supported the first synthesised finding. Findings included in the first category show that FAs are commonly referred from one healthcare professional to another. This makes the FAs feel that they are not receiving help with their condition (Olsson \& Hansagi, 2001; Wiklund-Gustin, 2013). They long for information about their problems and ways of improving their situation (Wiklund-Gustin, 2013).

Unfortunately, FAs often experience encounters with healthcare professionals as being confusing (Olsson \& Hansagi, 2001). If one healthcare professional cannot identify a transparent reason for an FA's condition, they are typically referred onwards or their care is discontinued, leaving them to manage their situation alone (Olsson \& Hansagi, 2001).

The second category is based on findings relating to the care received and cases in which its outcomes do not meet the FA's expectations (Hodgson et al., 2015; Sledge et al., 2011). Several FAs perceived their treatment to be unsatisfactory (Hodgson et al., 2015). Additionally, FAs expressed feelings of disappointment and frustration relating 
to some healthcare professionals' actions. For example, one FA felt that a physician who was late for an appointment nevertheless rushed through the consultation at the FA's expense (Sledge et al., 2011).

The third category is based on findings relating to the FAs' search for reassurance through consulting. The attitudes and approaches adopted by healthcare professionals during consultations can significantly influence FAs' future attendance (Hodgson et al., 2015; Neal et al., 2000). FAs who found their symptoms difficult to cope with sought reassurance from healthcare professionals (Hodgson et al., 2015) and consulted frequently to obtain a diagnosis for their symptoms (Neal et al., 2000). In some cases, receiving a diagnosis reduced the frequency of consultation. In other cases, receiving a diagnosis led to an increase in consultations because it caused FAs to worry about their condition and seek reassurance. Demands for reconsultation indicated that the FAs did not feel that they received sufficient reassurance for their needs. The ways in which the healthcare professionals received FAs influenced the extent to which the FAs considered frequent consultations necessary. For example, one FA said "At one point I did say to him, I said 'You must be sick of seeing my face'. He said, 'No', he said, 'that is what I am here for', he said, 'you come back as many times as you want'or 'as many times that you feel necessary until you get better', so I thought well, while I can do this I have not got to worry about anything. " (Neal et al., 2000). Once the consultations became an established practice, FAs felt that while they were received, the consultations passed quickly and nothing much seemed to happen. In contrast to other findings described above, where the frequent consultations originated from FAs themselves, the healthcare professionals could influence the FAs' reasons for reconsulting. The 
healthcare professionals instructed FAs to attend further consultations in the form of follow-up visits or if the FAs did not feel their condition to be improving (Neal et al., 2000).

\subsubsection{FAs' own expertise with their condition should be recognised and valued alongside the expertise of healthcare professionals when performing collaborative care}

Three categories supported the second synthesised finding. The first category related to the FAs' perceptions of the specialist-client relationship as a form of collaboration with the healthcare professional (Sledge et al., 2011). Some findings in this category showed that certain FAs recognised their own influence on the outcome of their relationship with the healthcare professional: “(...) How would she know how I feel if I don't say anything?" (Sledge et al., 2011). FAs were also forgiving of healthcare professionals' shortcomings; for example, they recognized that the healthcare professionals have heavy workloads, and so adopted a forgiving and understanding attitude (Sledge et al., 2011).

The second category relates to the FAs' desire for their own interpretation of their condition and situation to be valued and taken into consideration. FAs felt they were not taken seriously and that their interpretation of the situation was downplayed (Olsson \& Hansagi, 2001; Wiklund-Gustin, 2013). This appears to be partly due to healthcare professionals' mistrust and uncertainty about why the FAs were seeking care (Wiklund- 
Gustin, 2013). The FAs thus felt that instead of acknowledging their interpretation of the situation, the healthcare professionals were telling them how they ought to feel (Wiklund-Gustin, 2013). FAs also felt that their own assessment of the urgency of their need for care often differed from that of the healthcare professionals. FAs hoped that healthcare professionals would act respectfully if the FAs experienced their condition as requiring care (Olsson \& Hansagi, 2001).

The third category related to the FAs' respect for the healthcare professional's status as an authority and an expert in managing and treating their symptoms. Healthcare professionals (physicians in particular) were highly appreciated and were seen as appropriate people to turn to when needing help with health conditions (Hodgson et al., 2015). FAs were confident of getting proficient treatment (Sledge et al., 2011). FAs who had professionally-oriented relationships with their physicians emphasised the medical aspects of the relationship: "I just follow whatever she says and we talk, regular routine. Test the heart ... I've been through it." (Sledge et al., 2011) FAs considered the role of physicians to include not only treating symptoms but also providing help and support (Neal et al., 2000).

\subsubsection{A lack of empathy and disparagement may make FAs feel misunderstood and}

\section{unappreciated}

Four categories supported the third synthesised finding. The first category related to FAs' feelings of being disrespected or stigmatised by healthcare professionals. Some 
FAs felt they were disrespected by healthcare professionals and even discriminated against because of their sex or ethnic background (Mautner et al., 2013). FAs felt that some healthcare professionals regarded them as hypochondriacs or nuisances, not so much because their consultations were unnecessary but because they were excessively frequent (Neal et al., 2000). Other FAs believed that healthcare professionals did not think the FAs were actually sick and that their frequent attendance was actually due to benefit-seeking: "She didn't believe there was anything wrong with me. 'I can't see anything', she said. 'There is nothing wrong with you. You just don 't want to work'. I always heard those kinds of things. But it isn't true." (Wiklund-Gustin, 2013).

Findings in the second category related to FAs' perceptions of themselves as being unworthy of care. Some FAs saw themselves as burdens because of their symptoms, and felt that they were not understood by the healthcare professionals from whom they expected healing, leading to feelings of inadequacy and unimportance. This made the FAs believe that they should cope alone and should not receive care (Wiklund-Gustin, 2013).

The third category included findings relating to FAs' perception that healthcare professionals lacked empathy and diminished their needs. A lack of empathy increased FAs' stress levels and reduced patient satisfaction (Olsson \& Hansagi, 2011). The need for personal attention was highlighted when it was absent: "I just wish that he (her provider) would be more sensitive to my needs. More concerned about what happened 
to me as a childand that a lot of what to me is (the) cause of (my) obesity today."

(Sledge et al., 2011)

The fourth category included findings relating to FAs' feeling that healthcare

professionals did not understand them or their condition (Wiklund-Gustin, 2013). Some

FAs felt inclined to give up because nobody seemed to care about or understand their

situation. FAs felt it was easier to hide their true feelings. Others were more hopeful and believed that once the healthcare professionals figured out the problem, a solution would be found. The fact that the FAs' experiences are not heard is an obstacle in that it reduces healthcare professionals' ability to understand the FAs' problems and help them (Wiklund-Gustin, 2013).

\subsubsection{FAs should be recognised as individuals by taking their circumstances into account and providing support accordingly}

Three categories supported the fourth synthesised finding. The first was based on findings showing that FAs appreciated acknowledgement of their individual situation and conditions, and were pleased to be treated accordingly. FAs considered it important to be recognised as individuals (Sledge et al., 2011) and to feel cared for by healthcare professionals. They emphasised the importance of emotional support in their interactions with healthcare professionals; some reported positive experiences in this respect (Mautner et al., 2013) while others perceived a lack of recognition of their situation (Hodgson et al., 2015).

This article is protected by copyright. All rights reserved. 
The second category related to healthcare professionals' acknowledgement of nonmedical aspects of FAs' lives that the FAs considered important. Sledge et al. (2011) found that some FAs were concerned about interpersonal and social issues and considered it important for healthcare professionals to address them. Additionally, FAs appreciated having relationships with healthcare professionals in which the FAs got a sense of their meaning to the professional (Sledge et al., 2011).

Findings in the third category related to the extent to which healthcare professionals and the clinic generally make the customer feel welcome. The importance of established relationships with both healthcare professionals (Neal et al., 2000) and reception staff was emphasised: "I can go anytime, just phone up and they fit me in. The girls on the phone know me really well and always sort me out." (Hodgson et al., 2015) Many FAs had long-term and familiar relationship with their physicians (Neal et al., 2000), and regarded the clinic as a whole as warm welcoming place where they are well looked after (Sledge et al., 2011; Olsson \& Hansagi, 2001).

All four of the synthesized findings were assigned a low ConQual score (Table 4). Due to low scores of credibility and dependability, the results should be considered as suggestive.

\section{DISCUSSION}

This article is protected by copyright. All rights reserved. 
This review synthesised FAs' experiences of their encounters with healthcare personnel and provided information through recommendations for practice. The synthesised findings indicate that FAs become frustrated when they experience difficulties with resolving their situation and end up in service circles. FAs valued collaborative care that acknowledged their own experiences of their conditions as being complementary to healthcare professionals' expertise. FAs also appreciated being recognised as individuals with individual needs, but felt misunderstood and unappreciated due to a lack of empathy and disparagement.

The first synthesised finding showed that FAs are often referred from one healthcare professional to another when no apparent cause of their condition can be identified, leaving FAs uncertain about their situation. Although continuity of care is associated with a reduced frequency of healthcare visits (Barker et al., 2017) and coordination problems are associated with frequent attendance (Hudon et al., 2016), there does not seem to be a clearly identified individual or entity that takes responsibility for the overall situation of FAs. This may lead to discontinuous care (Vehko et al., 2018). Access is preferred to continuity when it comes to acute visits, but the reverse is true for preventive visits and chronic disease management (Ehman et al., 2017). Because many FAs require long-term care (LaCalle \& Rabin, 2010), continuity of care should be emphasised as a prerequisite for effective care. Loss of continuity strains patients because it requires them to repeatedly describe their situation and spend time establishing new relationships. Narrative notes have been used to document subjective 
experiences and can provide more in-depth information about the patient's situation (Finn, 2015). For FAs, whose situation can be multidimensional and hard to describe during a short consultation, narrative documentation could increase the effectiveness of care, especially in cases where contributions from several healthcare professionals are needed.

FAs are sometimes viewed as a patient group that imposes strain on the healthcare system and healthcare professionals. While the review indicates that FAs' reconsultations are often undertaken on their own initiative, they are also often referred on to new professionals or instructed to reconsult. When healthcare professionals indicate that such consultations are necessary, it may affect FA's consultation behaviour. Indeed, if healthcare professionals feel that they cannot identify the FA's reason for seeking consultation, they may actively encourage the FA's consultation behaviour (Taylor et al., 2012). It has been found that patients consider follow-up visits unnecessary more commonly than physicians (25\% vs. 11\%) (Wick \& Coller, 2005). However, the results of this review indicate that FAs seek repeated consultation even after receiving a diagnosis, which might be explained by the need for reassurance.

The second synthesised finding indicated that the basis of the care is formed by collaboration between healthcare professionals' expertise and FAs' experiential knowledge of their situation, although FAs considered healthcare professionals to be experts in managing their condition. Without a clear reason for attendance, it is difficult for healthcare professionals to act. Although healthcare professionals have a focal role 
in communication during consultations, the success of communication also depends on the patient's communication (Street, 2017). The findings of this review related mainly to healthcare professionals' role in consultations; the only finding related to the responsibilities of the FAs was that concerning collaborative care, which requires contributions from the patient. A lack of patient participation and failure to express feelings during consultations prevent healthcare professionals from becoming aware of the patient's overall situation (Street, 2017). Ganguli et al. (2017) observed misunderstandings between FAs and physicians because physicians did not always communicate clearly. To help FAs participate in their own care, healthcare professionals should provide medical information in a clear and simple way (Roh \& Park, 2016).

Despite FAs' willingness to participate in their care, FAs felt that their own interpretations of their situation were not adequately accounted for. In fact, even though shared decision-making is considered important, its application in practice is limited (Bodegard et al., 2019; Stiggelbout et al., 2015). Few researchers have investigated encounters between physicians and FAs from the viewpoints of both parties; to our knowledge, the only study to have taken such an approach is that of Smucker et al. (2001). They found that some physicians do not take FAs' symptoms or concerns into consideration, resulting in a lack of mutual interpretation of the situation. Accordingly, some FAs feel that their reasons for seeking care are disregarded and their interpretations are not valued. In contrast to the patient-centred approach, which emphasises the patient's participation, physician-centred communication focuses on the patient's disease and physical symptoms (Bientzle et al., 2017), and undervalues FAs' 
own interpretations. Because poor self-reported health is a significant predictor of frequent attendance (LaCalle \& Rabin, 2010), dismissal of FAs' need to consult and participate in care may result in recurring and prolonged consultations.

The third synthesised finding showed that some FAs feel that healthcare professionals lack empathy and disparage them. FAs do not only consider the medical aspects of consultations; they place equal or greater emphasis on their interaction with healthcare professionals. Patients consider empathy essential for a good relationship with healthcare professionals (Derksen et al., 2017) and expect healthcare professionals to listen and take interest in them (Derksen et al., 2018). Healthcare professionals tend to avoid discussing emotional issues when patients express concerns; instead, they focus on medical aspects (Mjaaland et al., 2011) or emphasise efficiency to make a diagnosis (Roh \& Park, 2016). Such a lack of empathy may lead to a lack of understanding and make it more difficult to solve the patient's problems (Derksen et al., 2017). Accordingly, FAs felt that healthcare professionals did not fully understand them or their needs.

Some FAs also experienced actual discrimination, in accordance with previous studies. Baggio et al. (2017) found that over 30 percent of FAs experienced some kind of discrimination from healthcare professionals, with disease, physical appearance, nationality and language being the most common reasons for discrimination. They also found that perceived discrimination was associated with poor self-reported health. This indicates that the way FAs are encountered may increase their feelings of inadequacy. 
Some FAs also felt that they did not deserve care, indicating that a lack of empathy may cause some to avoid consultations (Derksen et al., 2017). Previous negative experiences of consultations can also affect FAs' expectations of future healthcare encounters and may adversely affect their efforts to create trustful relationships with healthcare professionals.

The fourth synthesised finding states that FAs' individual situations should be acknowledged and used as a basis for action. Patients value long-term relationships with healthcare professionals because such relationships enable them to consult with professionals who are familiar with their wider situation and can use the consultation time efficiently (Waibel et al., 2012). Ratanawongsa et al. (2011) examined healthcare professionals' and patients' perspectives of their challenging relationships. Although healthcare professionals considered some relationships to be challenging due to a lack of process, the patients viewed these relationships positively because they felt that the professionals were dedicated to helping them with their situation.

In addition to taking medical aspects into account, FAs appreciate acknowledgement of other dimensions of their lives. In fact, one dimension of patient-centred care is the patient's biopsychological context, which relates to the patient's biological, psychological, and social circumstances (Street, 2017). Although patients and healthcare professionals often have different views about which health concerns should be prioritised, dealing first with a patient's other concerns may improve the management of medical conditions (Grant et al., 2013). FAs should be acknowledged as individuals 
with distinctive needs. Previous interventions targeted at FAs have yielded inconsistent results, and there is no clear evidence that they directly reduced FAs' attendance rates (Haroun et al., 2016). However, case management interventions in which services are "customised" according to the patient's needs have been found to reduce the frequency of healthcare visits (Hudon et al., 2020). Therefore, a more patient-centred approach to FAs' treatment and service planning may be beneficial.

The results presented here mainly relate to encounters between FAs and physicians. Although the contribution of reception staff was acknowledged in one of the studies, their roles in the encounters of FAs have not been clearly delineated. Reception staff are patients' first points of contact with healthcare services, and have been shown to play important roles; they can positively influence patients' healthcare experiences. Although the role of reception staff may be neglected when considering inter-professional collaboration, they could be considered members of the care team (Neuwelt et al., 2015). Interestingly, the roles of other healthcare professionals were also not well defined. However, only half of the included articles clearly specified which kinds of workers were regarded as healthcare professionals for the purposes of the corresponding study. Because other clinical staff such as nurses play significant and increasingly large roles in providing healthcare services, there is a need to study their influence on the encounters of FAs. Interventions using inter-professional approach have proven beneficial in FAs' care (Adam et al., 2010). For example, interventions can reduce the frequency of FAs' healthcare visits and improve their satisfaction with their care and well-being (Adam et al., 2010). 


\subsection{Limitations}

This review has some limitations. Only six studies were included in this review. Three of the categories were based on one study's results, which restricts the generalisability of the results. However, it also indicates need for further studies regarding the encounters of FAs. Despite the use of a systematic approach, some relevant studies may not have been included in the review. For example, term 'frequent flyer' could have been included in the search strategy. Using term 'cost' resulted in irrelevant results. However, for example term 'high cost patient' describes frequent attendance, and it is used especially if a FA is defined based on the healthcare costs caused. Also, terms describing frequent attendance were searched only in title field. There is a wide range of terms describing frequent attendance, and when this variety of terminology is considered, it leads to search results related to e.g. heavy use of alcohol or drugs. Thus, wider search (title-abstract-key words) would have resulted in an extensive amount of results. As English is not our native language, this may have affected the interpretation of the included studies' findings and further the formulation of the findings of this review.

Because the included studies focused mainly on physicians' roles, the results may not be directly generalisable to encounters between FAs and other healthcare professionals. Also, studies examining access to care (e.g. transportation and timeliness) were not included. The inclusion of such studies might have raised issues relating to issues such 
as integration, and could thus have resulted in a greater emphasis on referrals. However, the aim of this review was to focus on encounters, which occur during consultations rather than when the patient is seeking to receive healthcare services.

\section{CONCLUSIONS AND RELEVANCE FOR CLINICAL PRACTICE}

The FAs' experiences illustrate a need for shared decision-making and continuity of care with an emphasis on caring and goal-oriented relationships between healthcare professionals and FAs. This synthesis complements the identification of FAs' service needs. The focus of previous research has been on attributes identified through patient records (e.g. number of healthcare visits and health conditions), which does not provide a comprehensive conception of the factors that influence frequent attendance, and how FAs themselves experience their relation with the way their care is arranged. The results of this review could be used practically to guide the organisation of patient-centred healthcare services. For example, healthcare professionals should take into account that FAs care would benefit from acknowledging FAs' own expertise through shared decision-making and in providing collaborative care. The results demonstrate the importance of making good use of FAs as experts by experience, which enables patient participation at the meso level (e.g. in developing or assessing services). Additionally, they reveal a need to encourage healthcare professionals to acknowledge FAs as a patient group with heterogeneous and individual needs. Because the ways in which FAs are encountered affects their consultation behaviour, the results could be used to guide efforts to improve the responsiveness of healthcare systems to FAs' service needs 
through, for example, case management. Case managers are often nurses, thus they have an important role in evaluating and coordinating appropriate services for FAs throughout their care path, and ending up in service circles could be avoided.

\section{Author contributions:}

Study design: $\mathrm{MH}, \mathrm{OK}$

Data collection: $\mathrm{MH}, \mathrm{OK}, \mathrm{AT}$

Data analysis: MH, OK, AT, HK

Manuscript writing: $\mathrm{MH}, \mathrm{OK}, \mathrm{AT}, \mathrm{HK}$ 


\section{References}

Adam, P., Branderburg, D.1., Bremer, K.L., \& Nordstrom, D.1. (2010) Effects of team care of frequent attenders on patients and physicians. Families, Systems and Health, 28, 247-257. doi: 10.1037/a0020944.

Altin, S.V., \& Stock, S. (2016). The impact of health literacy, patient-centered communication and shared decision-making on patients' satisfaction with care received in German primary care practices. BMC Health Services Research, 30. doi: 10.1186/s12913-016-1693-y.

Baggio, S., Iglesias, K., Hugli, O., Burnand, B., O. Ruggeri, J.-B., Wasserfallen, K., ... Bodenmann, P. (2017). Associations between perceived discrimination and health status among frequent Emergency Department users. European Journal of Emergency Medicine, 24, 136-41. doi:10.1097/MEJ.0000000000000311.

Barker, I., Steventon, A., \& Deeny, S.R. (2017). Association between continuity of care in general practice and hospital admissions for ambulatory care sensitive conditions: Cross sectional study of routinely collected, person level data. BMJ, 356. doi:10.1136/bmj.j84.

Bowling, A., Rowe, G., Lambert, N., Waddington, M., Mahtani, K.R., Kenten, C., ... Francis, S.A. (2012). The measurement of patients' expectations for health care: A review and psychometric testing of a measure of patients' expectations. Health Technology Assessment, 16, 1-509. doi:10.3310/hta16300.

Burns, T.R. (2017). Contributing factors of frequent use of the emergency department: A synthesis. International Emergency Nursing, 35, 51-55. doi:10.1016/j.ienj.2017.06.001.

Delaney, L.J. (2018). Patient-centred care as an approach to improving health care in Australia. Collegian Journal, 25, 119-123. doi:10.1016/j.colegn.2017.02.005.

Denniston, C., Molloy, E., \& Rees C.E. (2018). 'I will never ever go back': patients' written narratives of health care communication. Medical Education, 52, 757-71. doi:10.1111/medu.13612.

Derksen, F.A.W.M., Hartman, T.O., Bensing, J., \& Lagro-Janssen, A. (2018). Empathy in general practice-the gap between wishes and reality: Comparing the views of patients and physicians. Family Practice, 35, 203-208. doi:10.1093/fampra/cmx080.

Derksen, F., Olde Hartman, T.C., van Dijk, A., Plouvier, A., Bensing, J., \& LagroJanssen, A. (2017). Consequences of the presence and absence of empathy during consultations in primary care: A focus group study with patients. Patient Education and Counseling, 100, 987-93. doi:10.1016/j.pec.2016.12.003.

Dinkel, A., Schneider, A., Schmutzer, G., Brähler E., \& Häuser W. (2016). Family physician-patient relationship and frequent attendance of primary and specialist health

This article is protected by copyright. All rights reserved. 
care: Results from a German population-based cohort study. Patient Education and Counseling, 99, 1213-1219. doi:10.1016/j.pec.2016.02.009.

Ehman, K.M., Deyo-Svendsen, M., Merten, Z., Kramlinger, A.M., \& Garrison, G.M. (2017). How preferences for continuity and access differ between multimorbidity and healthy patients in a team care setting. Journal of Primary Care \& Community Health, 8, 319-323. doi:10.1177/2150131917704556.

Finn, C. (2015) Narrative nursing notes in the electronic health record: A key communication tool. Online Journal of Nursing Informatics, 19.

Ganguli, I., Thompson, R.W., \& Ferris, T.G. (2017). What can five high cost patients teach us about healthcare spending?, Healthcare, 5, 204-213.

doi:10.1016/j.hjdsi.2016.12.004.

Grant, R.W., Adams, A.S., Bayliss, E.A., \& Heisler M. (2013). Establishing visit priorities for complex patients: A summary of the literature and conceptual model to guide innovative interventions. Healthcare, 1, 117-122.

doi:10.1016/j.hjdsi.2013.07.008.

Haroun, D., Smits, F., van Etten-Jamaludin, F., Schene, A., van Weert, H., \& ter Riet, G. (2016). The effects of interventions on quality of life, morbidity and consultation frequency in frequent attenders in primary care: A systematic review. European Journal of General Practice, 22, 71-82. doi:10.3109/13814788.2016.1161751.

Hinchey, S.A., \& Jackson, J.L. (2011). A cohort study assessing difficult patient encounters in a walk-in primary care clinic, predictors and outcomes. Journal of General Internal Medicine, 26, 588-594. doi:10.1007/s11606-010-1620-6.

Hodgson, P., Smith, P., Brown, T., \& Dowrick, C. (2005). Stories from frequent attenders: A qualitative study in primary care. Annals of Family Medicine, 3, 318-323. doi:10.1370/afm.311.

Hudon, C., Sanche, S., \& Haggerty J.L. (2016). Personal characteristics and experience of primary care predicting frequent use of emergency department: A prospective cohort study. PLoS One, 11. doi:10.1371/journal.pone.0157489.

Hudon, C., Chouinard, M-C., Aubrey-Bassler, K., Muhajarine, N. Bush, P., Danish, A., ... (2020). Case management in primary care for frequent users of health care services: a realist synthesis. Annals of Family Medicine, 18, 218-226.

Kitson, A., Marshall, A., Bassett, K., \& Zeitz, K. (2013). What are the core elements of patient-centred care? A narrative review and synthesis of the literature from health policy, medicine and nursing. Journal of Advanced Nursing, 69, 4-15. doi:10.1111/j.1365-2648.2012.06064.x.

Kivelä, K., Elo, S., \& Kääriäinen M. (2018). Frequent attenders in primary health care: A concept analysis. International Journal of Nursing Studies, 86, 115-124. doi:10.1016/j.ijnurstu.2018.06.003.

This article is protected by copyright. All rights reserved. 
Koskela, T.-H., Ryynänen, O.-P., \& Soini, E.J. (2010). Risk factors for persistent frequent use of the primary health care services among frequent attenders: A Bayesian approach. Scandinavian Journal of Primary Health Care, 28, 55-61. doi:10.3109/02813431003690596.

LaCalle, E., \& Rabin, E. (2010). Frequent Users of Emergency Departments: The Myths, the Data, and the Policy Implications. Annals of Emergency Medicine, 56, 4248. doi:10.1016/j.annemergmed.2010.01.032.

Langberg, E.M., Dyhr, L., \& Davidsen, A.S. (2019). Development of the concept of patient-centredness - A systematic review. Patient Education and Counseling, 102, 1228-1236. doi:10.1016/j.pec.2019.02.023.

Lockwood, C., Porrit, K., Munn, Z., Rittenmeyer, L., Salmond, S., Bjerrum, M., ... Stannard, D. (2017). Systematic reviews of qualitative evidence. The Joanna Briggs Institute. https://reviewersmanual.joannabriggs.org/

Lyons, T.W., Olson, K.L., Palmer, N.P., Horwitz, R., Mandl, K.D., \& Fine, A.M. (2017). Patients Visiting Multiple Emergency Departments: Patterns, Costs, and Risk Factors. Academic Emergency Medicine, 24, 1349-1357. doi:10.1111/acem.13304.

Maatz, A., Wainwright, M., Russell, A.J., Macnaughton, J., \& Yiannakou, Y. (2016). What's 'difficult'? A multi-stage qualitative analysis of secondary care specialists' experiences with medically unexplained symptom. Journal of Psychosomatic Research, 90, 1-9. doi:10.1016/j.jpsychores.2016.09.005.

Mautner, D.B., Pang, H., Brenner, J.C., Shea, J.A., Gross, K.S., Frasso, R., \& Cannuscio, C.C. (2013). Generating hypotheses about care needs of high utilizers: Lessons from patient interviews. Population Health Management, 16, S26-S33. doi:10.1089/pop.2013.0033.

Mjaaland, T.A., Finset, A.,. Jensen, B.F, \& Gulbrandsen, P. (2011). Physicians' responses to patients' expressions of negative emotions in hospital consultations: A video-based observational study. Patient Education and Counseling, 84, 332-37. doi:10.1016/j.pec.2011.02.001.

Munn, Z., Porritt, K., Lockwood, C., Aromataris, E., \& Pearson, A. (2014). Establishing confidence in the output of qualitative research synthesis: The ConQual approach. BMC Medical Research Methodology, 14. doi:10.1186/1471-2288-14-108.

Neal, R.D., Heywood, P.L., \& Morley, S. (2000). "I always seem to be there" - A qualitative study of frequent attenders. The British Journal of General Practice, 50, 716-723.

Neuwelt, P.M., Kearns, R.A., Browne, A.J. (2015) The place of receptionists in access to primary care: Challenges in the space between community and consultation. Social Science and Medicine, 133, 287-295. doi: 10.1016/j.socscimed.2014. 
Olsson, M., \& Hansagi, H. (2001). Repeated use of the emergency department: Qualitative study of the patient's perspective. Emergency Medicine Journal, 18, 430434. doi: 10.1136/emj.18.6.430

Ratanawongsa N., Wright, S.M., Vargo, E.M., \& Carrese, J.A. (2011). Challenges in primary care relationships: seeing it from both sides. Patient Education and Counseling, 85, 40-45. doi: 10.1016/j.pec.2010.07.042.

Roh, H., \& Park, K.H. (2016). A Scoping Review: Communication between Emergency Physicians and Patients in the Emergency Department. Journal of Emergency Medicine, 50, 734-43. doi:10.1016/j.jemermed.2015.11.002.

Salokekkilä, P. (2011). Encounters in health care - The voice of the patient. University of Eastern Finland. http://epublications.uef.fi/pub/urn_isbn_978-952-61-06243/urn_isbn_978-952-61-0624-3.pdf.

Sledge, W.H., Wieland, M., Sells, D., Walden, D., Holmberg, C., Lin, Z., \& Davidson, L. (2011). Qualitative study of high-cost patients in an urban primary care centre. Chronic Illness, 7, 107-119. doi:10.1177/1742395310388673.

Smucker, D.R., Zink, T., Susman, J.L., \& Crabtree B.F. (2001). A framework for understanding visits by frequent attenders in family practice. Journal of Family Practice, 50, 847-52.

Soril, L.J.J., Leggett, L.E., Lorenzetti, D.L., Noseworthy, T.W., \& Clement, F.M. (2016). Characteristics of frequent users of the emergency department in the general adult population: A systematic review of international healthcare systems. Health Policy, 120, 452-461. doi:10.1016/j.healthpol.2016.02.006.

Stiggelbout, A.M., Pieterse, A.H., \& De Haes, J.C.J.M. (2015). Shared decision making: Concepts, evidence, and practice. Patient Education and Counseling, 98, 1172-1179. doi:10.1016/j.pec.2015.06.022.

Street, R.L. (2017). The many "Disguises" of patient-centered communication: Problems of conceptualization and measurement. Patient Education and Counseling, 100, 2131-2134. doi:10.1016/j.pec.2017.05.008.

Street, R.L., \& Haidet, P. (2011). How well do doctors know their patients? Factors affecting physician understanding of patients' health beliefs. Journal of General Internal Medicine, 26, 21-27. doi:10.1007/s11606-010-1453-3.

Taylor, R.E., Marshall, T., Mann, A., \& Goldberg, D.P. (2012). Insecure attachment and frequent attendance in primary care: A longitudinal cohort study of medically unexplained symptom presentations in ten UK general practices. Psychological Medicine, 42, 855-864. doi:10.1017/S0033291711001589.

Vedsted P., \& Christensen, M.B. (2005). Frequent attenders in general practice care: A literature review with special reference to methodological considerations. Public Health, 119, 118-137. doi:10.1016/j.puhe.2004.03.007. 
Vehko, T., Jolanki, O., Aalto, A.-M., \& Sinervo, T. (2018). How do health care workers manage a patient with multiple care needs from both health and social care services? A vignette study. International Journal of Care Coordination, 21, 5-14. doi:10.1177/2053434517744070.

Waibel, S., Henao, D., Aller, M.B., Vargas, I., \& Vázquez, M.L. (2012) What do we know about patients' perceptions of continuity of care? A meta-synthesis of qualitative studies. International Journal for Quality in Health Care, 24, 39-48. doi: 10.1093/intqhc/mzr068.

Wammes, J.J.G., Van Der Wees, P.J., Tanke, M.A.C., Westert, G.P., \& Jeurissen, P.P.T. (2018). Systematic review of high-cost patients' characteristics and healthcare utilisation. BMJ Open, 8. doi:10.1136/bmjopen-2018-023113.

Wick, A., \& Koller, T. (2005). Views of patients and physicians on follow-up visits: results from a cross-sectional study in Swiss primary care. Swiss Medical Weekly, 135, $9-10$.

Wiklund-Gustin, L. (2013). Struggling on my own: A cognitive perspective on frequent attenders' conception of life and their interaction with healthcare system. Psychiatry Journal. http://dx.doi.org/10.1155/2013/580175.

This article is protected by copyright. All rights reserved. 


\section{PRISMA 2009 Flow Diagram}
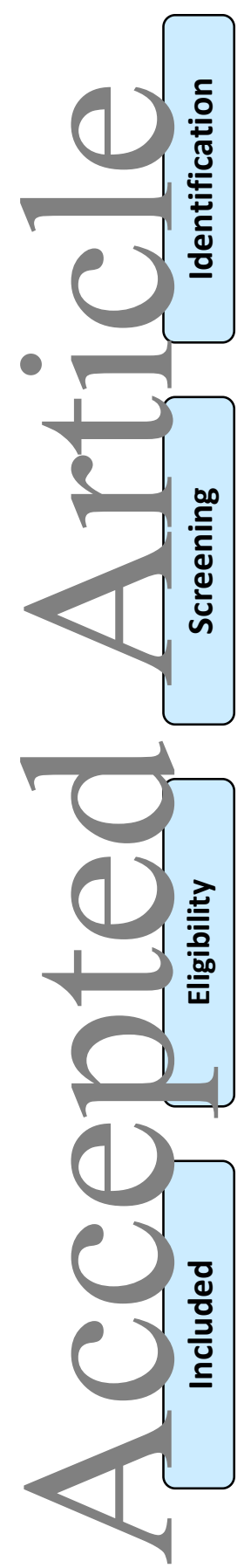

Records identified through database searching $(n=4469)$
Additional records identified through other sources

$(\mathrm{n}=2)$

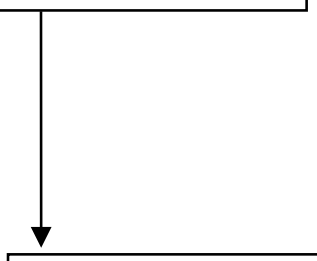
title and abstract $(\mathrm{n}=1774)$ $(\mathrm{n}=1794)$

Titles and abstracts screened after duplicates

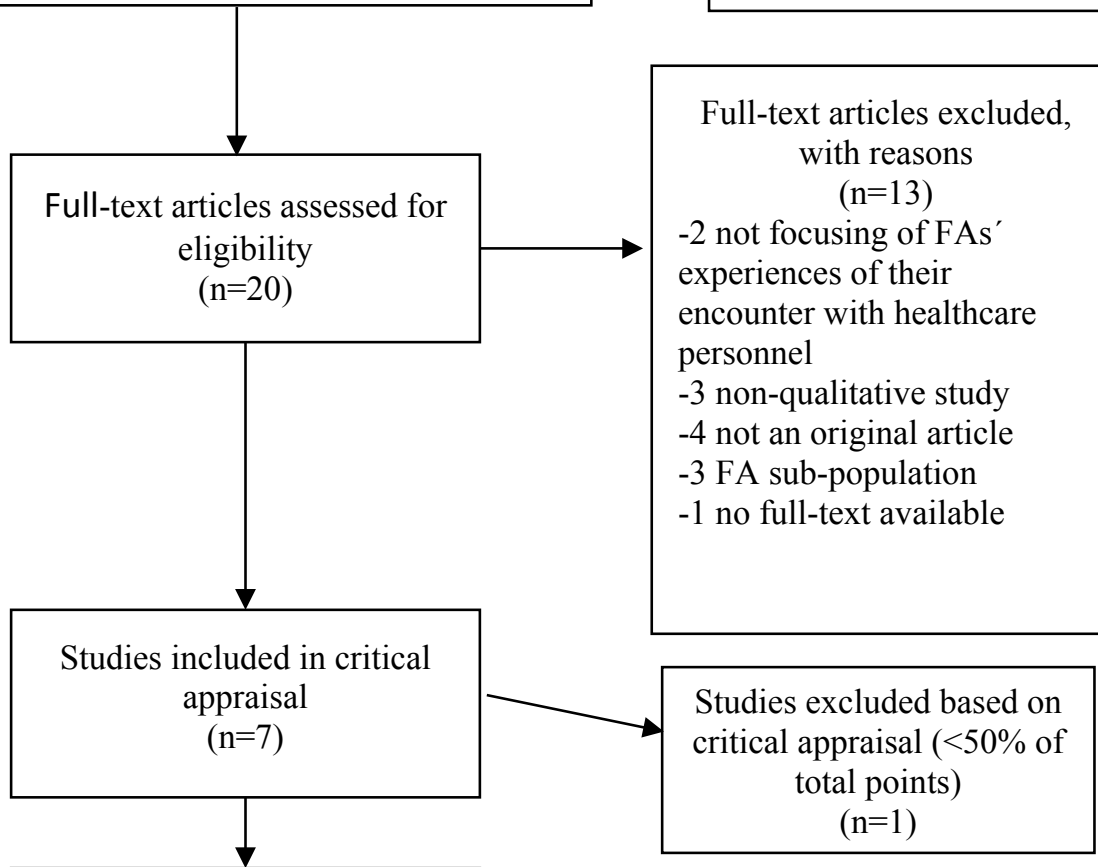

Studies included in qualitative synthesis $(\mathrm{n}=6)$

From: Moher D, Liberati A, Tetzlaff J, Altman DG, The PRISMA Group (2009). Preferred Reporting Items for Systematic Reviews and MetaAnalyses: The PRISMA Statement. PLoS Med 6(7): e1000097. doi:10.1371/journal.pmed1000097

For more information, visit www.prisma-statement.org. 
Table 1. Search strategies.

\begin{tabular}{|c|c|c|c|}
\hline \multirow{6}{*}{$\bullet$} & Database & Search strategy & Results \\
\hline & CINAHL & $\begin{array}{l}\text { TI ((frequent* OR high* OR heav* OR repeat*) W3 (use* OR attend* OR visit* OR } \\
\text { utili* OR hospitali* consult* OR cost*)) AND (MH "Attitude to Health+" OR MH } \\
\text { "Continuity of Patient Care+" OR "Decision Making, Patient+" OR MH "Health } \\
\text { Services Accessibility+" OR MH "Health Services Needs and Demand+" OR MH } \\
\text { "Patient Attitudes" OR MH "Professional-Patient Relations+" OR MH "Decision } \\
\text { Making, Shared" OR MH "Needs Assessment" OR participat* OR perceive* OR } \\
\text { perception* OR attitude* OR expect* OR satisfaction OR involve* OR relations*) }\end{array}$ & 1067 \\
\hline & PsycARTICLES & $\begin{array}{l}\text { TI (frequent* OR high* OR heav* OR repeat*) W3 (use* OR attend* OR visit* OR } \\
\text { utili* OR hospitali* OR consult* OR cost*) AND (participat* OR perceive OR } \\
\text { perception* OR attitude* OR expect* OR satisfaction OR involve* OR relations*) }\end{array}$ & 23 \\
\hline & PubMed (Medline) & $\begin{array}{l}\text { (frequent attend*[Title] OR frequent use*[Title] OR frequent hospitali*[Title] OR } \\
\text { frequent utili*[Title] OR frequent visit*[Title] OR frequent consult*[Title] OR high } \\
\text { utili*[Title] OR high cost*[Title] OR high attend*[Title] OR high use*[Title] OR } \\
\text { repeated use*[Title]) AND (“Attitude to Health"[Mesh] OR "Health Services } \\
\text { Accessibility"[Mesh] OR "Health Services Needs and Demand"[Mesh] OR } \\
\text { "Continuity of Patient Care" [Mesh] OR "Decision Making, Shared" [Mesh] OR } \\
\text { "Professional-Patient Relations" [Mesh] OR "Needs Assessment [Mesh] OR } \\
\text { participat*[Text Word] OR perceive [Text Word] OR perception*[Text Word] OR } \\
\text { attitude*[Text Word] OR expect*[Text Word] OR satisfaction[Text Word] OR } \\
\text { involve*[Text Word] OR relations[Text Word]) }\end{array}$ & 703 \\
\hline & Scopus & $\begin{array}{l}\text { TITLE ((frequent* OR high* OR heav* OR repeat*) PRE/3 (use* OR attend* OR } \\
\text { visit* OR utili* OR hospitali* OR consult* OR cost*)) AND TITLE-ABS-KEY } \\
\text { (participat* OR perceive OR perception* attitude* OR expect* OR satisfaction OR } \\
\text { involve* OR relations*) }\end{array}$ & 2676 \\
\hline & MedNar (grey literature) & $\begin{array}{l}\text { "frequent attend*" OR "frequent use*” OR "frequent hospitali*” OR "frequent utili*" } \\
\text { OR "frequent visit*" "frequent consult*” OR "high utili*” OR "high cost*” OR "high } \\
\text { attend"” OR "high use*” OR "repeated use*” }\end{array}$ & 377 \\
\hline
\end{tabular}

This article is protected by copyright. All rights reserved. 
Table 2 Data extraction. FA=frequent attender

\begin{tabular}{|c|c|c|c|c|c|}
\hline $\begin{array}{l}\text { First author } \\
\text { (year of } \\
\text { publication) } \\
\text { country }\end{array}$ & Purpose & $\begin{array}{l}\text { Participants, definition for a } \mathrm{FA}, \\
\text { parties regarded as healthcare } \\
\text { personnel during encounters. }\end{array}$ & $\begin{array}{l}\text { Methodology: study } \\
\text { setting, data } \\
\text { collection, data } \\
\text { analysis }\end{array}$ & Key findings & $\begin{array}{l}\text { Critical } \\
\text { appraisal }\end{array}$ \\
\hline $\begin{array}{l}\text { Hodgson } \\
(2005) \text { UK }\end{array}$ & $\begin{array}{l}\text { To explore how FAs view } \\
\text { their rates of consultation, } \\
\text { what they expect from the } \\
\text { consultation, and how they } \\
\text { perceive their relationship } \\
\text { with the primary healthcare } \\
\text { team. }\end{array}$ & $\begin{array}{l}30 \text { FAs. } \\
\text { First, patients whose consultation rates } \\
\text { were at least twice the mean annual } \\
\text { rate for each practice, stratified by sex } \\
\text { and four age ranges were identified. } \\
\text { Second, if patients' family doctors } \\
\text { judged the patient to have "no } \\
\text { significant clinical outcome", the } \\
\text { patient was considered as a FA. } \\
\text { Healthcare personnel included family } \\
\text { physicians and clinic staff. }\end{array}$ & $\begin{array}{l}\text { Four primary care } \\
\text { practices. } \\
\text { In-depth semi- } \\
\text { structured individual } \\
\text { interviews. } \\
\text { Thematic analysis. }\end{array}$ & $\begin{array}{l}\text { Family physicians were seen as authority } \\
\text { figures. FAs sought reassurance from } \\
\text { physicians. Expectations of the } \\
\text { consultations were complex; both old and } \\
\text { new symptoms were expected to be } \\
\text { addressed. }\end{array}$ & $6 / 10$ \\
\hline $\begin{array}{l}\text { Mautner } \\
\text { (2013) USA }\end{array}$ & $\begin{array}{l}\text { To characterise FAs and } \\
\text { their perceptions of their } \\
\text { health and healthcare, and } \\
\text { to identify barriers and } \\
\text { facilitators to health and } \\
\text { healthcare from these } \\
\text { patients' perspectives. }\end{array}$ & $\begin{array}{l}19 \text { FAs. } \\
\text { No clear definition of a FA. } \\
\text { Included healthcare personnel not } \\
\text { specified. }\end{array}$ & $\begin{array}{l}\text { Former patients of the } \\
\text { Care Management } \\
\text { Team intervention. } \\
\text { Semi-structured } \\
\text { individual interviews. } \\
\text { A modified grounded } \\
\text { theory analysis. }\end{array}$ & $\begin{array}{l}\text { Participants reported difficult encounters } \\
\text { with healthcare providers and emphasised } \\
\text { the importance of being cared for by } \\
\text { providers. }\end{array}$ & $7 / 10$ \\
\hline $\begin{array}{l}\text { Neal (2000) } \\
\text { UK }\end{array}$ & $\begin{array}{l}\text { To determine why FAs } \\
\text { consult in the patterns that } \\
\text { they do and thereby } \\
\text { develop a model to capture } \\
\text { the main features of this. }\end{array}$ & $\begin{array}{l}28 \text { FAs. } \\
\text { Top } 150 \text { adult attenders in each of the } \\
\text { three practices. } \\
\text { Healthcare personnel were physicians. }\end{array}$ & $\begin{array}{l}\text { Primary care (three } \\
\text { general practices). } \\
\text { Semi-structured } \\
\text { individual interviews. } \\
\text { Thematic analysis. }\end{array}$ & $\begin{array}{l}\text { FAs identified broad roles for GPs, e.g. } \\
\text { being there if needed. FAs perceived that } \\
\text { their GP saw them as a nuisance because } \\
\text { of frequent consulting. Well established } \\
\text { relationships with a GP were reported. The } \\
\text { effect of making a diagnosis and lack of } \\
\text { internal control had an impact on } \\
\text { consultation frequency. }\end{array}$ & $6 / 10$ \\
\hline $\begin{array}{l}\text { Olsson (2001) } \\
\text { Sweden }\end{array}$ & $\begin{array}{l}\text { To explore patients' } \\
\text { reasons for repeatedly } \\
\text { turning to the ED and their } \\
\text { experiences of these } \\
\text { medical encounters }\end{array}$ & $\begin{array}{l}10 \text { FAs who had each made } \\
6-17 \text { ED visits in the previous year and } \\
\text { did not require particularly specialised } \\
\text { medical care. } \\
\text { Included healthcare personnel not } \\
\text { specified. The emergency department } \\
\text { included specialists in different fields. }\end{array}$ & $\begin{array}{l}\text { An emergency } \\
\text { department of a } \\
\text { university hospital. } \\
\text { Individual interviews } \\
\text { with open questions. } \\
\text { Inductive analysis. }\end{array}$ & $\begin{array}{l}\text { Participants wanted their reasons for } \\
\text { seeking help to be respected, and reported } \\
\text { not receiving adequate help or empathy. }\end{array}$ & $8 / 10$ \\
\hline
\end{tabular}

This article is protected by copyright. All rights reserved. 
I will never receive any help. The participants experience themselves as being shuffled around between different GPs never obtaining any answers as to what is wrong or what could be done. (U) (Wiklund-Gustin, 2013)

Respondents have on some occasion been referred from the ED to a psychiatrist. The

encounters at the psychiatric clinic were for all informants connected with an ambiguous outcome and few seem to have received adequate help. They were further referred and/or treatment was discontinued (C) (Olsson, \& Hansagi, 2001)

Despite holding their doctors in high regard, slightly more than two thirds of the interviewees expressed some form of dissatisfaction with their treatment (U) (Hodgson et al., 2005)

To express feelings of disappointment more strongly in the face of frustration such as long waits. The participant was focused on the idea that her physician tried to deceive her and furthermore, attempted to make up for poor management by rushing her. The participant was angry and willing to represent the failure as entirely the physician's

fault. (C) (Sledge et al., 2011)

Some patients described experiencing a relatively high number of physical sensations

that were difficult for them to endure and required reassurance from their family doctor

(U) (Hodgson et al., 2005)

The GP's behaviour during the consultation, and the outcome of the consultation, were both powerful influences in determining future patterns of attendance. The effect of

making a diagnosis, or of delays in diagnosing, had an impact on subsequent consulting, with some patients consulting frequently in search of a diagnosis and then less so when

diagnosed, and others consulting frequently once diagnosed (C) (Neal et al., 2000)

Frequent attenders explicitly consulted for continued reassurance, the fact that they

continued to consult suggested that they were not effectively reassured (U) (Neal et al., 2000)

Frequent attenders often received feedback from the GP on the appropriateness of their consulting; invariably it was appropriate and justified, legitimising their ongoing

consulting. Once into an established pattern of consulting, responders felt that they were quickly 'in and out' of the consultation, and that 'nothing much' seemed to happen in the consultation. (C) (Neal et al., 2000)

Many respondents reported 'having to go' for check-ups or being 'told to come back' (U) (Neal et al., 2000)

prone to see themselves in a relationship in which they bore some responsibility for its outcome (U) (Sledge et al., 2011)

be forgiving and to offer excuses for lateness and other shortcomings. A participant was
Category

FAs feel they are referred from one

healthcare professional to another

Synthesised finding

Difficulties in resolving FAs' situations may create service circles, making patients frustrated with their situation

The care received and its outcomes do not meet FAs' expectations

FAs seek reassurance through consulting, during which the healthcare professional can significantly increase FAs' future attendance

FAs regard specialist-client relationships as collaborations with healthcare professionals
FAs' own expertise with their condition should be recognised and valued alongside the expertise of healthcare professionals

This article is protected by copyright. All rights reserved. 
willing to allow himself the comfort of an excuse, namely that the staff are busy with large caseloads that they cannot help (U) (Sledge et al., 2011)

Experience of being put aside and neglected when attending for care, a sense of not being taken seriously. - they experience that the staff mistrust and question their causes for attending and therefore put them off. This will nourish their conception that they must be healthy to be treated seriously, and/or that other people's opinions are more trustworthy than their own, as their own description of the situation is not taken into account. Instead, it is others who tell them the truth about how they really feel, or at least ought to feel. (U) (Wiklund-Gustin, 2013)

Informants emphasised that they want their interpretation of the symptoms and their choice to seek urgent help to be respected. She - feels ambivalent about seeking care at the ED, but because of unbearable pain, she visits the ED, aware that her own

judgement of urgency often differs from that of the staff (C) (Olsson, \& Hansagi, 2001) family doctors as having high esteem and status (U) (Hodgson et al., 2005)

emphasize and focus on the medical aspects of the relationship (U) (Sledge et al., 2011)

The belief that a family doctor was the most appropriate and obvious person to manage and treat their symptoms (U) (Hodgson et al., 2005)

The respondents behaved in ways that responded to what they regarded the GP to be for. Three broad roles for a GP were identified, with responders often describing more than one: 1) to talk to, to be there if needed, be a friend; 2) to provide help and/or advice; 3) to find out what is wrong, treat symptoms, make people better, and to reassure (C) (Neal et al., 2000)

patients' degree of confidence predicated on technical proficiency (U) (Sledge et al., 2011)

Most of the stories of negative health care encounters focused on feeling disrespected from providers, while others specifically described feeling discriminated against by

\section{providers because of race or sex. (U) (Mautner et al., 2012)}

The participants strive against a suspicion that other people mistrust and question them and their motives. An experience that is described often is that other people, healthcare staff as well as friends and colleagues, believe that they are actually not sick, and that they attend the healthcare centre just to get advantages (U) (Wiklund-Gustin, 2013) Frequent attenders perceived that their GP thought they were a nuisance or a

hypochondriac, because of frequent, rather than inappropriate, consulting (U) (Neal et al., 2000)

Other people do not understand me, especially not the healthcare staff that are supposed to help them. This will too nourish the patients' beliefs that they are inadequate and not significant as persons. Thus, the negative spirals will go on, the person believes that he/she has to manage on his/her own and that he/she is not entitled to care. (C) (Wiklund-Gustin, 2013) when performing collaborative care

FAs want their own interpretation of their condition and situation to be valued and taken into consideration

FAs respect the healthcare professional as an authority and expert in managing and treating their symptoms

FAs feel they are disrespected or stigmatised by healthcare professionals

A lack of empathy and disparagement may make FAs feel misunderstood and unappreciated

This article is protected by copyright. All rights reserved. 
Feeling of being a burden because of symptoms (U) (Wiklund-Gustin 2013)

a perceived lack of empathy increases their distress. Patient satisfaction with care seems

to decrease when the ED staff devalue the symptoms presented (C) (Olsson, \& Hansagi,

2001)

At times, the importance of quality of personal attention was emphasised by its absence

(U) (Sledge et al., 2011)

Behind the façade dwells an experience of resignation. There is no use showing how

one really feels as nobody will care or understand. It seems more appropriate, and

easier, to put on a happy face and hide behind that. (U) (Wiklund-Gustin, 2013)

Something might be done that changes everything. However, rooted in the participants

experiences of not being listened to, this subcategory thus reflects a glimpse of hope. As

the participant believes that the GP has not really understood the problem, there is hope

that when this understanding appears, there will also be an appropriate treatment for the

patient's problem (U) (Wiklund-Gustin, 2013)

Half of participants indicated the importance of "feeling cared for" by providers (...) the importance of the emotional supportive interactions (U) (Mautner et al., 2012)

participants stressed the value of being recognized as individuals $(\mathrm{C})$ (Sledge et al.,

2011)

The ability of family doctors to be part of an individual's unique suffering. Furthermore,

the extreme - and for this interviewee unique - circumstances of his suffering were perceived to be unnoticed by clinicians. (U) (Hodgson et al., 2005)

Of particular importance to these patients was a relationship that extended beyond a

focus on the medical complaint being addressed to other dimensions of their lives

important to their well-being which included the person's sense of what he or she mean

to the doctor (U) (Sledge et al., 2011)

concerned about a variety of non-medical topics that the physician could or did address

with them, mostly interpersonal and social matters (U) (Sledge et al., 2011)

A minority reported friendly relationships with reception staff (U) (Hodgson et al.,

2005)

Most responders reported long-term familiarity with their GP and well established relationships (U) (Neal et al., 2000)

the clinic as an extension of their own home and more as "friends" (U) (Sledge et al.,

2011)

A patient has often been afraid of being treated as a "regular" at the emergency

department, but he feels that so far he has been well looked after (U) (Olsson, \&

Hansagi, 2001)
FAs perceive a lack of empathy and

feel their needs are diminished

FAs feel the healthcare professionals do not understand them or their condition

FAs appreciate having their individual situation and condition acknowledged and being treated accordingly

FAs should be recognised as individuals by taking their circumstances into accoun and providing support accordingly
FAs value healthcare professionals also acknowledging other (non-

medical) aspects of their life that they consider important.

FAs emphasised the role of healthcare professionals' and the clinic as a whole in making FAs feel welcomed 
Table 4 ConQual: summary of findings

\begin{tabular}{|c|c|c|c|c|c|c|}
\hline Synthesised finding & Studies & $\begin{array}{l}\text { Type of } \\
\text { research }\end{array}$ & Dependability & Credibility & $\begin{array}{l}\text { ConQual } \\
\text { Score }\end{array}$ & Comments \\
\hline $\begin{array}{l}\text { Difficulties in resolving FAs' situations } \\
\text { may create service circles, making } \\
\text { patients frustrated with their situation }\end{array}$ & $\begin{array}{l}\text { Wiklund- } \\
\text { Gustin } \\
\text { Olsson } \\
\text { Hodgson } \\
\text { Sledge } \\
\text { Neal }\end{array}$ & Qualitative & $\begin{array}{l}\text { Moderate } \\
\text { (downgraded one } \\
\text { level) }\end{array}$ & $\begin{array}{l}\text { Moderate } \\
\text { (downgraded } \\
\text { one level) }\end{array}$ & Low & $\begin{array}{l}\text { Dependability downgraded: of } 5 \text { primary } \\
\text { studies, two studies addressed } 4-5 \\
\text { dependability questions (ranking remains } \\
\text { unchanged); three studies addressed } 2-3 \\
\text { dependability questions (ranking downgraded } \\
\text { one level). } \\
\text { Credibility downgraded due to mix of U and C } \\
\text { findings ( } 5 \mathrm{U}+4 \mathrm{C}) \text {. }\end{array}$ \\
\hline $\begin{array}{l}\text { FAs' own expertise with their } \\
\text { condition should be recognised and } \\
\text { valued alongside the expertise of } \\
\text { healthcare professionals when } \\
\text { performing collaborative care }\end{array}$ & $\begin{array}{l}\text { Sledge } \\
\text { Wiklund- } \\
\text { Gustin } \\
\text { Olsson } \\
\text { Hodgson } \\
\text { Neal }\end{array}$ & Qualitative & $\begin{array}{l}\text { Moderate } \\
\text { (downgraded one } \\
\text { level) }\end{array}$ & $\begin{array}{l}\text { Moderate } \\
\text { (downgraded } \\
\text { one level) }\end{array}$ & Low & $\begin{array}{l}\text { Dependability downgraded: of five primary } \\
\text { studies, two studies addressed } 4-5 \\
\text { dependability questions; three studies addressed } \\
2-3 \text { dependability questions. } \\
\text { Credibility downgraded due to mix of } U \text { and } C \\
\text { findings }(7 \mathrm{U}+2 \mathrm{C}) \text {. }\end{array}$ \\
\hline $\begin{array}{l}\text { A lack of empathy and disparagement } \\
\text { may make FAs feel misunderstood and } \\
\text { unappreciated }\end{array}$ & $\begin{array}{l}\text { Mautner } \\
\text { Wiklund- } \\
\text { Gustin } \\
\text { Neal } \\
\text { Olsson } \\
\text { Sledge }\end{array}$ & Qualitative & $\begin{array}{l}\text { Moderate } \\
\text { (downgraded one } \\
\text { level) }\end{array}$ & $\begin{array}{l}\text { Moderate } \\
\text { (downgraded } \\
\text { one level) }\end{array}$ & Low & $\begin{array}{l}\text { Dependability downgraded: of five primary } \\
\text { studies, two studies addressed } 4-5 \\
\text { dependability questions; three studies addressed } \\
2-3 \text { dependability questions. } \\
\text { Credibility downgraded due to mix of } U \text { and } C \\
\text { findings }(7 \mathrm{U}+2 \mathrm{C}) \text {. }\end{array}$ \\
\hline $\begin{array}{l}\text { FAs should be recognised as } \\
\text { individuals by taking their } \\
\text { circumstances into account and } \\
\text { providing support accordingly }\end{array}$ & $\begin{array}{l}\text { Mautner } \\
\text { Sledge } \\
\text { Hodgson } \\
\text { Neal } \\
\text { Olsson }\end{array}$ & Qualitative & $\begin{array}{l}\text { Moderate } \\
\text { (downgraded one } \\
\text { level) }\end{array}$ & $\begin{array}{l}\text { Moderate } \\
\text { (downgraded } \\
\text { one level) }\end{array}$ & Low & $\begin{array}{l}\text { Dependability downgraded: of five primary } \\
\text { studies, one study addressed } 4-5 \text { dependability } \\
\text { questions; four studies addressed } 2-3 \\
\text { dependability questions. } \\
\text { Credibility downgraded due to mix of } U \text { and C } \\
\text { findings }(8 \mathrm{U}+1 \mathrm{C}) \text {. }\end{array}$ \\
\hline
\end{tabular}

Note. As part of the JBI's guidelines for systematic reviews of qualitative evidence, the ConQual approach was used to establish confidence in the evidence. In the ConQual

summary of findings, the ConQual score was calculated for each synthesised finding. The overall ConQual score can be high, moderate, low or very low. The ConQual Score

was calculated as follows: first, included studies were ranked as high. When ConQual Score is calculated, the score may stay as the same or downgrade based on

dependability and/or credibility. Thus second, included studies were graded for dependability, which was based on five questions from critical appraisal criteria (Table 2,

questions Q2-Q4, Q6, Q7). The score downgraded one level if two or three responses to the five questions were yes, and two levels if none or one questions were yes. Third,

This article is protected by copyright. All rights reserved. 
level of credibility was assessed for each synthesised finding according to assessments of levels of plausibility. Levels of plausibility were assessed based on the congruence between a finding and the accompanying illustration; each finding was classified as being unequivocal, equivocal, or unsupported. If findings included classifications of both unequivocal and equivocal, the score downgraded one level. If findings were classified as equivocal, the score downgraded two levels. (Munn, et al., 2014). 